\title{
AÇÕES DE EDUCAÇÃO EM SAÚDE PARA PREVENÇÃO DA COVID-19 POR MEIO DA UTILIZAÇÃO DE MÍDIAS SOCIAIS
}

Jamires Silva de Souza ${ }^{1}$ Brenda Ferreira de Figueredo ${ }^{1}$

Vanessa Alves Aquino ${ }^{1}$

Jomel Francisco dos Santos ${ }^{1}$

SOUZA, J. S. de; FIGUEREDO, B. F. de; AQUINO, V. A.; SANTOS, J. F. dos. Ações de educação em saúde para prevenção da Covid-19 por meio da utilização de mídias sociais. Arquivos de Ciências Veterinárias e Zoologia da UNIPAR, Umuarama, v. 23, n. 2cont., e2306, 2020.

RESUMO: O vírus Sars-CoV-2 causa a doença mais recente caracterizada como ameaça à saúde global e possui, principalmente, curso de doença respiratória. Os principais sintomas podem ser febre, tosse e dispneia e o risco pode aumentar conforme a idade e a presença de outras doenças associadas no paciente. Atualmente o tratamento é de suporte e ainda não há vacina. A maioria das estratégias globais de resposta ao combate dessa doença inclui níveis variados de rastreamento de contato e autoisolamento ou quarentena, sendo essas as melhores formas de prevenção e também a maneira de evitar maior disseminação da enfermidade. Devido ao isolamento social para prevenção da doença, uma das alternativas que podem ser utilizadas para proporcionar informação e educação em saúde para a população em geral é por meio dos meios de comunicação em massa. Dessa forma, o objetivo deste trabalho consistiu em utilizar mídias sociais como ferramenta para sensibilizar a população quanto à prevenção da COVID-19, com o intuito de ofertar e facilitar o acesso a informações de cunho educativo. A seleção da mídia social, assim como sua plataforma de interação contribuíram para a apresentação de resultados satisfatórios relacionados aos conteúdos publicados para disseminação das informações inerentes à doença.

PALAVRAS-CHAVE: Síndrome respiratória. Pandemia. Educação em saúde. Prevenção.

\section{HEALTH EDUCATION ACTIONS TO PREVENT COVID-19 THROUGH THE USE OF SOCIAL MEDIA}

\begin{abstract}
The Sars-CoV-2 virus causes the most recent disease characterized as a threat to global health and has, mainly, a course of respiratory disease. The main symptoms can be fever, cough and dyspnea and the risk may increase with age and the presence of other associated diseases in the patient. Currently the treatment is supportive and there is still no vaccine. Most global response strategies to combat this disease include varying levels of contact screening and self-isolation or quarantine, which is the best form of prevention and also a way to avoid further spread of the disease. Due to social isolation for disease prevention, one of the alternatives that can be used to provide health information and education to the general population is through mass media. Thus, the objective of this work was to use social media as a tool to sensitize the population about the prevention of COVID-19, in order to offer and facilitate access to educational information. The selection of social media, as well as its interaction platform, contributed to the presentation of satisfactory results related to the content published for dissemination of information inherent to the disease.
\end{abstract}

KEYWORDS: Respiratory syndrome. Pandemic. Health education. Prevention.

\section{ACCIONES DE EDUCACIÓN PARA LA SALUD PARA PREVENIR COVID-19 MEDIANTE EL USO DE LAS REDES SOCIALES}

RESUMEN: El virus Sars-CoV-2 causa la enfermedad más reciente caracterizada como una amenaza para la salud mundial y tiene principalmente un curso de enfermedad respiratoria. Los principales síntomas pueden ser fiebre, tos y disnea y el riesgo puede aumentar con la edad y la presencia de otras enfermedades asociadas en el paciente. Actualmente el tratamiento es de apoyo y todavía no hay ninguna vacuna. La mayoría de las estrategias de respuesta mundial para combatir esta enfermedad incluyen diversos niveles de detección de contactos y de autoaislamiento o cuarentena, que es la mejor forma de prevención y también una manera de evitar una mayor propagación de la enfermedad. Debido al aislamiento social para la prevención de enfermedades, una de las alternativas que se pueden utilizar para proporcionar información y educación sanitaria a la población en general es a través de los medios de comunicación. Así pues, el objetivo de esta labor era utilizar los medios de comunicación social como instrumento para sensibilizar a la población acerca de la prevención del COVID-19, a fin de ofrecer y facilitar el acceso a la información educativa. La selección de los medios de comunicación social, así como su plataforma de interacción, contribuyeron a la presentación de resultados satisfactorios relacionados con los contenidos publicados para la difusión de la información inherente a la enfermedad.

PALABRAS CLAVE: Síndrome respiratorio. Pandemia. Educación sobre la salud. Prevención.

DOI: 10.25110 /arqvet.v23i2cont.2020.8185

'Instituto Federal de Educação, Ciência e Tecnologia do Amazonas, Campus Zona Leste, Brasil. jamiressilvadesouza99@gmail.com 


\section{Introdução}

O novo Coronavírus (Sars-CoV-2) é um vírus identificado como a causa de um surto de doença respiratória detectado pela primeira vez em 2019, na cidade de Wuhan, província de Hubei na República Popular da China, onde houve vários casos de pneumonia, alertados à Organização Mundial da Saúde - OMS (ORGANIZAÇÃO PANAMERICANA DE SAÚDE, 2020).

A doença COVID-19 possui sintomas iniciais não específicos (CASCELLA et al., 2020; HANI et al., 2020). Até o momento não há medicamento específico para o tratamento da Infecção Humana pelo novo Coronavírus (Sars-CoV-2). No entanto, medidas de suporte devem ser implementadas de acordo com o caso clínico apresentado, tendo em vista que cada paciente manifesta a doença de forma diferenciada, indo de um quadro assintomático até o mais complexo com graves quadros de infecções pulmonares, onde o paciente necessitará de um cuidado mais delicado baseado principalmente no fornecimento de oxigênio e ventilação mecânica (VARGAS et al., 2020).

A prevenção é a principal forma para evitar a expansão do número de casos da doença e o principal fator para isso consiste no isolamento social, segundo a WHO (2020). É importante fortalecer medidas rígidas de higiene para prevenção e controle da doença em locais públicos como supermercados, hospitais e outros departamentos de medicina em emergência, pessoas que pertencem ao grupo de risco devem evitar saídas constantes e locais com grande público (WHO, 2020).

Diante dessa problemática, a Educação em Saúde além de contribuir para a formação da consciência crítica das pessoas a respeito da doença, que partindo da realidade, estimula a busca de medidas preventivas e ações tanto de forma individual quanto coletiva, a Educação em Saúde é uma prática social que produz o desenvolvimento da aplicação de saberes destinados ao desenvolvimento humano, havendo um consenso sobre o relevante papel de ações de promoção da saúde e de educação em saúde desenvolvidas dentro das escolas e instituições (PAES; PAIXÃO, 2016; PINAFO et al., 2012).

Diante do exposto, este trabalho teve como objetivo sensibilizar a população e verificar o conhecimento da mesma quanto à prevenção da COVID-19, por meio da utilização de mídias sociais, com o intuito de ofertar e facilitar o acesso a informações de cunho educativo.

\section{Material e Métodos}

Para o desenvolvimento deste trabalho, foram realizadas as seguintes atividades: revisão bibliográfica de cunho descritivo e exploratório sobre o novo coronavírus (Sars-CoV-2) e doença (COVID-19) realizada nas bases de dados Google Scholar, PubMed e Periódicos Capes sobre o tema; confecção de mídias informativas, uso das mídias sociais, aplicação de questionário online através do Google Forms ${ }^{\circledR}$ criado com o intuito de avaliar o nível de conhecimento da população a ser entrevistada sobre a pandemia do novo coronavírus (Sars-CoV-2) e doença (COVID-19) e o papel dos canais de comunicação na propagação de informações falsas e verdadeiras. A validação das tecnologias foi realizada por meio da interação do público com o conteúdo publicado nas redes sociais, e análise estatística de forma descritiva com auxílio de planilhas do Microsoft Excel das respostas coletadas no questionário durante o tempo em que o mesmo ficou disponível. Foram qualificados e quantificados por meio da análise do conhecimento dos participantes e assim foram validadas as tecnologias aplicadas sobre o tema.

A criação de mídia informativa foi realizada por meio de cartilhas em formato PDF e postagens educativas de fácil entendimento ao público em geral, onde a elaboração do material ocorreu através de pesquisa bibliográfica e sites oficiais referentes ao tema.

Para a criação da rede social e disseminação de informações interativas e confiáveis através de postagens, a rede Instagram ${ }^{\circledR}$ foi a escolhida. Criada em abril de 2020, contabilizou não só com o compartilhamento de stories diários informativos no próprio perfil, mas também com os de perfis oficiais de saúde e de autoridades locais, estaduais e nacionais como: Ministério da Saúde, Fundação Oswaldo Cruz (Fiocruz), British Broadcasting Corporation- Brasil (BBC- Brasil), Secretaria de saúde da Bahia, Secretaria Municipal da Saúde de Manaus, SEMSA - Manaus, Prefeitura de Manaus - AM, Prefeitura de Teresina- PI e Governo do Estado do Amazonas.

O preenchimento do questionário online foi de forma anônima e voluntária, de ordem qualitativa e quantitativa. O instrumento ficou disponível durante dez dias para que fosse respondido pelo maior número de pessoas possíveis com o intuito de alcançar diversos grupos da sociedade em geral. Os questionamentos foram formulados com base nos seguintes pontos: novo coronavírus (Sars$\mathrm{CoV}$-2) e doença (COVID-19) e o papel dos canais de comunicação na propagação de informações verdadeiras e falsas.

\section{Resultados e Discussão}

Ao todo foram distribuídas 200 cartilhas, divididas entre os temas "Coronavírus (COVID-19): O que você precisa saber? e "Coronavírus (COVID-19) e os pets: O que você precisa saber sobre seu melhor amigo" (Figura 1 e 2). Foram recebidos 140 comentários positivos; 60 pessoas não se manifestaram sobre o material recebido. Meinert et al. (2011) afirmam que a experiência educativa vivenciada com o uso da cartilha constitui-se um importante meio de informar, transmitir conhecimentos e promover reflexão acerca da saúde e bem-estar da sociedade. A cartilha ainda é um importante material didático para atividades de educação em saúde com o objetivo de repassar o conhecimento científico para o público alvo (OLIVEIRA et al., 2014). 
Figura 1: Cartilha Coronavírus (COVID-19): O que você precisa saber?

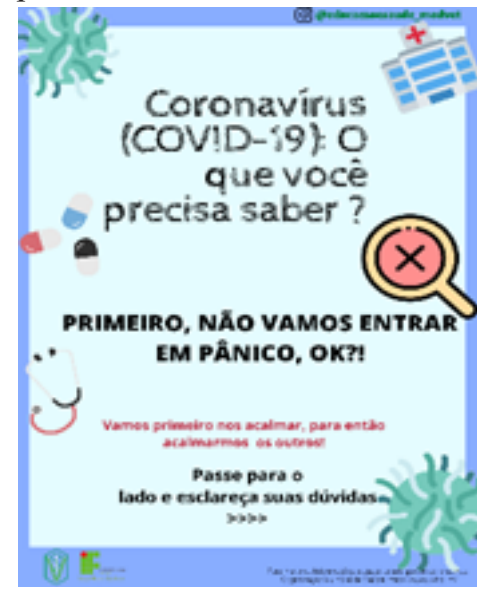

Fonte: os autores (2020).

Figura 2: Cartilha "Coronavírus (COVID-19) e os pets: O que você precisa saber sobre seu melhor amigo.

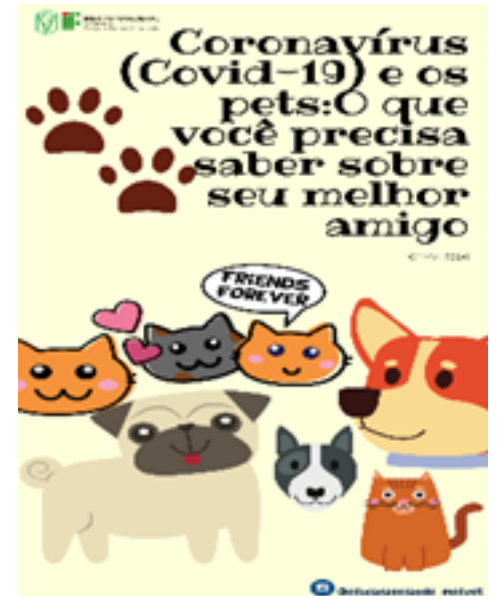

Fonte: os autores (2020)

As cartilhas foram elaboradas com a finalidade de sensibilizar a população assistida de maneira objetiva e de fácil entendimento. Ressalta-se ainda que para obter a efetividade da cartilha educativa, é necessário o planejamento eficaz da equipe, assim como a dinamicidade e a criação de propostas que garantam a participação e aprendizagem de aspectos significativos da doença em questão (MEINERT et al., 2011).

Os informativos foram elaborados com linguagem acessível, ilustrações atraentes e comunicação clara e objetiva. Dessa forma, conseguiu atrair a atenção e interesse das pessoas à leitura conforme orientado por Oliveira et al. (2014).

O médico veterinário é um sanitarista por excelência e tem o papel de disseminar informação à população leiga. A educação em saúde é uma excelente maneira de não apenas sensibilizar o grupo assistido, como também os tornar propagadores em potencial desse conhecimento (PAES; PAIXÃO, 2016). Grippo e Fracolli (2008) consideram que a educação em saúde representa um recurso de interação de conhecimentos oriundos no campo da saúde representando um processo educativo o qual favorece o desenvolvimento da autonomia por meio da articulação dos conhecimentos adquiridos.
Para que as ações de educação em saúde sejam eficazes, são necessárias metodologias que prendam a atenção do público e também os direcione ao ponto forte do tema abordado, para tanto, os questionários são muito eficazes, pois, após a aplicação do mesmo os assistidos têm vontade de saber qual é a resposta e então passam a buscá-la e prestar mais atenção quando esse ponto é abordado (SANTOS et al., 2019).

O uso de mídias sociais, apresentou resultados satisfatórios em relação as publicações criadas para o perfil (a)educacaoesaude_medvet na rede social Instagram $\AA$ (Figura 3). A partir da realização de 15 publicações e stories diários. Evidenciado a média de 200 visitas ao perfil semanalmente, aumento no número de seguidores, sendo $60,1 \%$ dos entrevistados acadêmicos da área da saúde e um alcance médio de 230 pessoas por publicação (Figura 4).

Figura 3: Perfil@educacaoesaude_medvet na rede social Instagram.

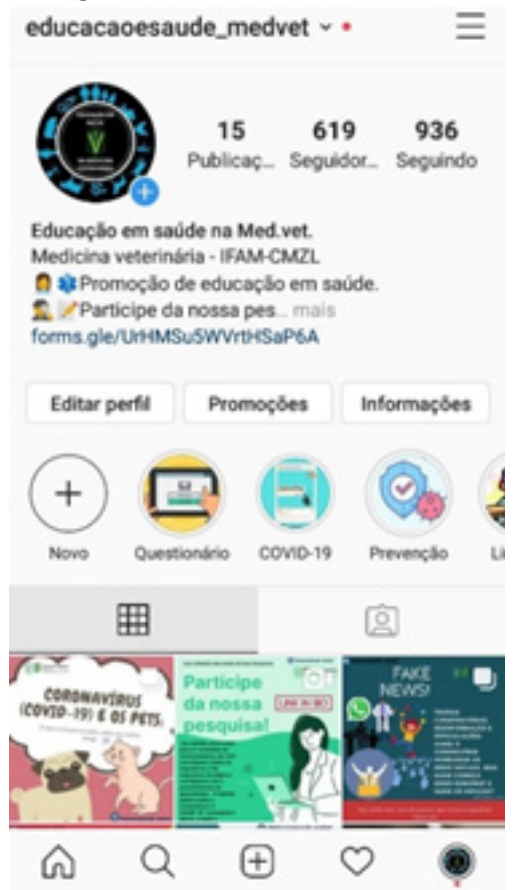

Figura 4: Acessos ao perfil.
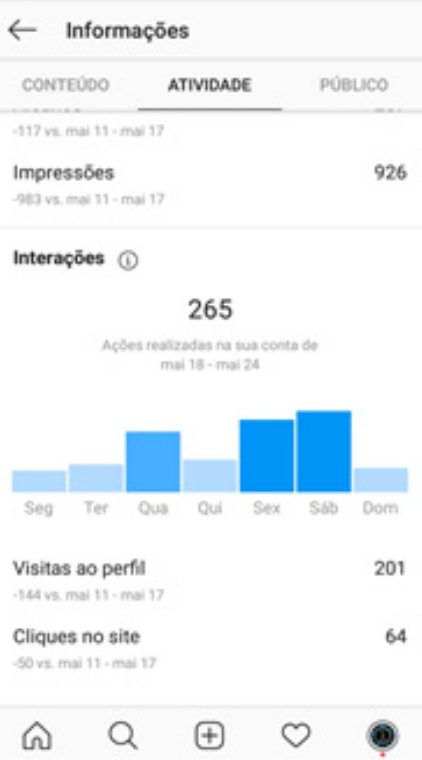
A tecnologia aplicada na pesquisa foi em formato online pelo Google forms ${ }^{\circledR}$, a qual resultou no total de 278 respostas abrangendo um público de todos os estados brasileiros, sendo $80 \%$ dos participantes eram residentes de Manaus-AM. Os autores Chaer et al. (2011) demonstraram que o questionário é uma metodologia apropriada para ser empregada quando se trata de problemas cujos objetos de pesquisa correspondem à questões de cunho empírico, envolvendo opinião, percepção, posicionamento e preferências dos pesquisados.

O público de 18-24 anos representou $60,1 \%$ do público total e os mesmos alegaram ter maior conhecimento sobre o assunto. Segundo Rosado e Tomé (2015) os jovens são curiosos e se mostram ativos as informações aos ambientes digitais pelo alto grau de participação nas redes sociais. Para os participantes do estudo com 80 anos ou mais o seu sistema de crenças favorece um comportamento negligente, pois estão menos receptivos a novas informações, acreditam ter risco médio de contaminação, acham que a pandemia será menor no Brasil e que temos uma proteção maior para a COVID-19, já os jovens apresentam um maior cuidado em relação a doença (LIMA et al., 2020).

O grau de escolaridade dos participantes foi de $52,2 \%$ para o Ensino superior incompleto. Com relação às perguntas realizadas com o grupo total, $97,8 \%$ das pessoas alegaram saber o que é o novo coronavírus. Ao associarmos essa pergunta ao gênero analisamos que o público feminino apresentou (52\%) um maior conhecimento sobre a doença em relação ao público masculino (48\%). Em estudo de Lima et al. (2020) o gênero feminino acredita mais na gravidade dessa doença que os homens, fato explicado devido ao maior senso de autocuidado das mulheres. Isso pode interferir até na taxa de infecção que de acordo com Chen et al. (2020), observaram que um número maior de homens foi contaminado pela COVID-19 em relação as mulheres.

As redes sociais usadas com maior frequência pelos entrevistados foram WhatsApp ${ }^{\circledR}$ e Instagram ${ }^{\circledR}$ com $93,9 \%$ e $88,8 \%$, respectivamente. As fontes de maior confiança para o recebimento de informações consideradas pelos participantes foram: Ministério da saúde, Organização Mundial de Saúde e telejornais. As fontes não confiáveis consideradas pelo público foram WhatsApp ${ }^{\circledR} 79,9 \%$ e Facebook ${ }^{\circledR} 73,4 \%$. Segundo Castro et al. (2020) é cada vez mais importante a manutenção da sociabilidade e informações em condições excepcionais de isolamento social. Assim o uso das redes sociais disponibilizando o monitoramento do vírus, possibilitado por diversas instituições, por exemplo, tem ajudado as pessoas a se manterem informadas sobre o contexto mundial, bem como o acesso a informações de fontes seguras.

Quando questionados sobre essas atualizações/ posts serem verdadeiras, 65,5\% dos entrevistados consideraram a alternativa "Alguns". Ao associarmos essa pergunta a faixa etária, foi observado que pessoas com idade entre 18-24 anos acreditam que apenas algumas informações sejam verdadeiras. Na pergunta sobre já terem compartilhado alguma notícia falsa, mesmo que sem querer, $73 \%$ alegaram que "não". Ao compararmos essa questão ao gênero observamos que, $60 \%$ das mulheres entrevistadas alegaram que não compartilharam informações falsas sobre a COVID-19. Já em relação à faixa etária os jovens entre
18-24 anos alegaram não terem compartilhado notícias falsas, mesmo que sem querer.

O compartilhamento de informações falsas pode resultar em problemas sérios e implica grande responsabilidade em quem o faz, além de dificultar o trabalho dos profissionais de saúde em relação à prevenção e os cuidados sobre a COVID-19 (SOUSA JÚNIOR et al., 2020).

Dos entrevistados, 29,5\% marcou a opção de terem saído "Apenas 1 vez por semana" de suas residências. Segundo estudo de Bezerra et al. (2020), concluíram que a percepção das pessoas quanto ao isolamento social como medida de combate à pandemia, varia conforme a renda, escolaridade, idade e sexo, porém a maior parte acredita que se trata da medida de controle mais indicada e estão dispostos a esperar o tempo que for necessário para contribuir com o enfrentamento à COVID-19, fato comprovado pela presente pesquisa devido ao quantitativo de respostas obtidas.

Quando questionados sobre as medidas de prevenção, 97,8\% dos entrevistados afirmaram que usam máscaras quando necessitam sair de casa. Em relação à população de forma geral, o seu uso é recomendado principalmente para quem está infectado. Como a doença tem um período de incubação de 14 dias, nem sempre as pessoas sabem que estão infectadas, portanto a utilização ampla das máscaras tem sido recomendada (BORNSTIN et al., 2020). A pesquisa mostrou que, 57,2\% disseram não terem tido contato com algum portador de COVID-19; Sobre a higienização das compras em estabelecimentos essenciais ao chegarem em casa, 78,7\% alegaram que higienizavam as mesmas. Para sanitização de superfícies, materiais e utensílios, o recomendado é que se utilize solução de álcool na concentração $70 \%$ ou solução de água sanitária (hipoclorito de sódio) na concentração de $0,1 \%$, conforme recomendação da Organização Mundial da Saúde (WHO, 2020).

Com relação às crenças sobre a COVID-19, o questionário revelou que $75,5 \%$ dos entrevistados acreditam que os animais de estimação não podem transmitir a doença; mas, 44,2\% acreditam que a COVID-19 teve origem em morcegos ou outros animais. Essa afirmativa pode ser justificada por um fato histórico, vivenciado em meados de 2003, de que esse mamífero foi indicado como um provável agente de disseminação da SARS (síndrome respiratória aguda grave) causada pelo coronavírus SARS-CoV (DO BÚ et al., 2020).

Para finalizar o questionário havia uma opção em que o participante marcaria se procuraria mais informação sobre a COVID-19 após ter preenchido o mesmo, onde $46,4 \%$ dos entrevistados alegaram que procurariam maiores informações sobre o tema. Esses dados corroboram com a pesquisa feita por Sousa Junior et al. (2020) que realizou a análise da utilização do termo "coronavírus", por meio da ferramenta Google Trends ${ }^{\circledR}$ e pesquisas de Fake News onde concluiu que concomitante a toda essa exposição midiática que a pandemia tem causado, o número de buscas na internet tem demonstrado alto crescimento e evidenciado que a população não está isenta da dimensão da problemática, mas está buscando informações que a orientem e os auxiliem nesse momento tão delicado e este projeto teve o intuito de expor informações confiáveis e claras para os participantes e demais pessoas da comunidade que tiverem interesse em 
acessar o Instagram ${ }^{\circledR}$.

\section{Conclusão}

A pandemia continua em andamento e o número de casos continuam surgindo diariamente, o que reforça a necessidade de divulgação e manutenção sobre as medidas sanitárias para o controle e prevenção da doença. Muitas variáveis clínicas ainda estão em processo de estudo e comparação com outros acometimentos virais anteriores. Certamente, haverá um crescimento no número de artigos, nas patentes e nos estudos clínicos. No entanto, até a data do presente trabalho não existe, de fato, uma vacina com eficácia comprovada mundialmente, porém muitos países estão em processos de pesquisa da formulação de vacinas.

A utilização de questionário online o qual foi criado baseado no nível de conhecimento da população sobre a pandemia do novo coronavírus e o papel dos canais de comunicação na propagação de informações foram importantes instrumentos para o entendimento da percepção populacional a respeito das notícias, prevenção e crenças sobre a COVID-19 de maneira quantitativa e qualitativa.

Dada a importância do assunto, torna-se necessário continuar o projeto com a divulgação de informações sanitárias, fontes com informações verdadeiras, cartilhas e publicações diárias para alcançar um número maior de indivíduos e dessa forma contribuir para a formação da consciência crítica a respeito da doença e a manutenção da prevenção da mesma.

\section{Referências}

BEZERRA, A. C. V. et al. "Fatores associados ao comportamento da população durante o isolamento social na pandemia de COVID-19". Ciências e Saúde Coletiva, Manguinhos, v. 25, n. 6, p. 2411-2421, 2020.

BORNSTIN, V. J. et al. O que mais podemos saber sobre o novo coronavírus e a Covid-19? Rio de Janeiro: EPSJV, 2020. 17 p.

CASCELLA, M. R. et al. Evaluation and treatment Coronavirus (COVID-19). StatPearls Publishing. Treasure Island (FL), 2020. p. 1-44.

CASTRO, D. et al. Capitalismo e a Covid-19- um debate urgente. São Paulo, 2020. p. 45.

CHAER, G. et al. A técnica do questionário na pesquisa educacional. Evidência, Araxá, v. 7, n. 7, p. 251-266, 2011.

CHEN, N. et al. Epidemiological and clinical characteristics of 99 cases of 2019 novel coronavirus pneumonia in Wuhan, China: a descriptive study. The Lancet. New Englad, v. 395, n. 10223, p. 507-513, 2020.

DO BÚ, E. A. et al. Representações e ancoragens sociais do novo coronavírus e do tratamento da COVID-19 por brasileiros. Estudos de Psicologia (Campinas). Disponível em: http://www.scielo.br/scielo.php?script=sci_arttext\&pi $\mathrm{d}=\mathrm{S} 0103166 \mathrm{X} 2020000100505 \& \operatorname{lng}=\mathrm{en} \& \mathrm{nrm}=\mathbf{i}$ iso. Acesso em: 27 maio 2020.

GRIPPO, M. L. V. S.; FRACOLLI, L. A. Avaliação de uma cartilha educativa sobre promoção do cuidado à criança na percepção da família sobre saúde e cidadania. Revista da Escola de Enfermagem USP, São Paulo, v. 42, n. 3, p. 430-436, 2008.

HANI, C. et al. COVID-19 pneumonia: A review of typical CT findings and differential diagnosis. Diagnosis Interventionist Imaging, v. 101, n. 5, p. 263-268, 2020.

LIMA, D. L. F. et al. COVID-19 no estado do Ceará, Brasil: comportamentos e crenças na chegada da pandemia. Ciência \& Saúde Coletiva, Rio de Janeiro, v. 25, n. 5, p. 1575-1586, 2020.

MEINERT, L. et al. Elaboração de cartilha educativa para paciente diabético como intervenção psicológica: um trabalho multiprofissional. Psicologia para América Latina, México, n. 22, p. 1-14, 2011.

OLIVEIRA, S. C. et al. Desenvolvimento e validação de um folheto educacional para alimentação saudável durante a gravidez. Revista Latino-Americana de Enfermagem, Ribeirão Preto, v. 22, n. 4, p. 611-620, 2014.

Organização Pan-Americana de Saúde. Folha informativa COVID-19 - Escritório da OPAS e da OMS no Brasil. 2020. Disponivel em: https://www.paho.org/pt/covid19. Acesso em: 29 maio 2020.

PAES, C. C. D. C.; PAIXÃO, A. N. P. A. A importância da abordagem da educação em saúde. Revista De Educação Da Universidade Federal Do Vale Do São Francisco, v. 6, n. 11, p. 80-90, 2016.

PINAFO, E. et al. A educação em saúde na relação usuáriotrabalhador no cotidiano de equipes de saúde da família. Ciência e Saúde Coletiva, Rio de Janeiro, v. 17, n. 7, p. 1825-1832, 2012.

ROSADO, L. A.; TOMÉ, V. M. As redes sociais na internet e suas apropriações por jovens brasileiros e portugueses em idade escolar. Revista Brasileira de Estudos Pedagógicos, v. 96, n. 242, 2015.

SANTOS, R. A.; FIGUEREDO, B. F.; AZEVEDO FILHO, P. C. G.; SANTOS, J. F. Educação em saúde: ações de prevenção da tuberculose em instituições de ensino na cidade de Manaus, Amazonas. Nexus, revista de extensão do IFAM, n. 9, ano 5, dez. 2019.

SOUSA JÚNIOR, J. H. et al. Da Desinformação ao Caos: uma análise das Fake News frente à pandemia do Coronavírus (COVID-19) no Brasil. Cadernos de Prospecção, Salvador, v. 13, n. 2, p. 331-346, 2020.

VARGAS, A. R.; FERREIRA, A. C. N. N. J.; DIANA, P. M .C.; SUASSUNA, T. D. S. Protocolo de tratamento do novo coronavírus (2019-nCoV). 1. ed. Ministério da 
Saúde: Brasília-DF, Brasil, 2020. p. 13.

WHO. World Health Organization. 2020. Disponível em: https://covid19.who.int/. Acesso em: 29 maio 2020.

Recebido em: 30.09 .2020

Aceito em: 20.11.2020 